\title{
Sputum microbiology predicts health status in COPD
}

Dionne CW Braeken ${ }^{1,2}$

Sarah Houben-Wilke'

Dionne E Smid'

Gernot GU Rohde 2

Jesse JC Drijkoningen ${ }^{2}$

Emiel FM Wouters ${ }^{1,2}$

Martijn A Spruit ${ }^{1}$

Frits ME Franssen ${ }^{1,2}$

'Department of Research and Education, CIRO, Horn, the Netherlands; ${ }^{2}$ Department of Respiratory Medicine, Maastricht University Medical Centre (MUMC+), Maastricht, the Netherlands
Correspondence: Dionne CW Braeken Department of Research and Education, CIRO, PO Box 4009, 6080 AB Haelen, the Netherlands

Tel +3। 475587602

Email dionnebraeken@ciro-horn.nl
This article was published in the following Dove Press journal:

International Journal of COPD

7 November 2016

Number of times this article has been viewed

Background: Spontaneous sputum production occurs in a subset of COPD patients; however, its clinical relevance has not been established. Differences in health status and clinical outcomes between patients with and without positive sputum cultures are unknown.

Objective: To compare clinical characteristics and health status of spontaneous sputum producers with a positive culture $(\mathrm{SC}+)$ and negative culture $(\mathrm{SC}-)$ with nonsputum producers (NP) in a cohort of COPD patients referred for pulmonary rehabilitation.

Methods: In total, 518 clinically stable patients with mild-to-very severe COPD were recruited (mean age: $64.1 \pm 9.1$ years, $55.6 \%$ males, forced expiratory volume in 1 second $48.6 \% \pm 20.0 \%$ predicted). Health status was measured using COPD Assessment Test, St George's Respiratory Questionnaire, and the Clinical COPD Questionnaire. Symptoms of anxiety and depression were assessed using the Hospital Anxiety and Depression Scale. Exercise capacity was measured using the 6-minute walking distance. Spontaneously expectorated sputum was cultured for microbiology.

Results: Almost one-third of patients spontaneously produced sputum ( $n=164,31.7 \%)$. Despite comparable lung function, $\mathrm{SC}+$ reported more frequent exacerbations than NP ( $\geq 2$ exacerbations $<1$ year: 43 [81.1\%] vs 179 [50.6\%], $P<0.001)$. COPD Assessment Test total score and the Clinical COPD Questionnaire total score were significantly worse in SC+ than NP (23.9 $\pm 6.1 \mathrm{vs}$ $21.1 \pm 6.7, P=0.012 ; 3.1 \pm 1.0$ vs $2.5 \pm 1.0, P=0.002$; respectively). Hospital Anxiety and Depression Scale-D score was significantly higher in $\mathrm{SC}+$ than NP (8.7 \pm 4.1 vs $7.2 \pm 4.3, P=0.046)$.

Conclusion: Spontaneous sputum production is common in COPD. Particularly, patients with positive cultures have worse health status and more symptoms of depression. Impact on disease progression and long-term outcomes remain to be established.

Clinical trial registration: NTR3416, registered at www.trialregister.nl.

Keywords: COPD, health status, sputum, microbiology, pulmonary rehabilitation

\section{Introduction}

COPD is a life-threatening lung disease and is the fourth leading cause of death worldwide. ${ }^{1}$ It is known that COPD has a great impact on a patient's life. Symptoms frequently reported by patients with COPD are dyspnea, wheezing, cough, and sputum production. $^{2}$

For many years, the concept chronic bronchitis (CB) has been investigated in patients with COPD. The proportion of patients reporting $\mathrm{CB}$, defined as chronic productive cough, varies from $24.5 \%{ }^{3}$ to $82 \%{ }^{4}$ Research concerning CB focused mainly on disease progression, ${ }^{3,4}$ with reduced forced expiratory volume in 1 second $\left(\mathrm{FEV}_{1}\right)$ and Tiffeneau index (ratio $\mathrm{FEV}_{1} /$ forced vital capacity [FVC]) as end points, in comparison to nonpersistent sputum producers. ${ }^{3,4}$ Furthermore, different studies observed an increase in the number of exacerbations ${ }^{3,4}$ and hospitalizations, ${ }^{4}$ as well 
as a higher mortality risk. ${ }^{5}$ Subsequently, a reduced quality of life ${ }^{6}$ and functional exercise capacity ${ }^{3}$ have been previously reported.

Not all patients have symptoms of productive cough; some have only increased mucus production. Mucus hypersecretion $(\mathrm{MH})$ is characterized by an increase in mucin-producing cells, leading to increased mucus secretion. ${ }^{7} \mathrm{CB}$ and $\mathrm{MH}$ can simultaneously exist, although Caramori et $\mathrm{al}^{8}$ concluded that there was no link between symptoms of $\mathrm{CB}$ and mucus production. $\mathrm{MH}$ was related to $\mathrm{FEV}_{1}$ decline, hospitalization, ${ }^{9}$ and exacerbation frequency. ${ }^{10}$ Contrary results have been published concerning the association with mortality. ${ }^{11}$

Although data are available on $\mathrm{CB}$ and $\mathrm{MH}$, little is known about the association of spontaneous sputum production at any moment and health status and other clinical outcomes in patients with COPD. Especially, the potential impact of sputum microbiology on these outcomes might be clinically relevant because a substantial proportion of stable patients with COPD are colonized with bacteria, ${ }^{12}$ which is associated with increased daily symptoms ${ }^{13}$ and exacerbation frequency. ${ }^{14}$ Banerjee et $\mathrm{al}^{15}$ reported a worse health status in stable COPD patients with a positive sputum culture compared to patients without bacterial pathogens in sputum. These last data were limited because the focus of the research was different, and substantial information is lacking (eg, no mean values, only $P$-values).

Therefore, the aim of the present study was to increase understanding of the impact of spontaneous sputum production on health status and clinical characteristics in patients with COPD, after stratification between those with and without positive sputum cultures.

\section{Materials and methods}

The current analyses were based on data collected as part of the COPD, health status, and comorbidities (Chance) study, an observational monocenter study. ${ }^{16}$ The rationale and design of the study have been previously published. ${ }^{16}$ Chance was approved on April 23, 2012 by the local ethics committee of the Maastricht University Medical Centre+, the Netherlands (MEC 11-3-070). The authors confirm that all ongoing and related trials are registered (NTR3416, registered at www.trialregister.nl). All patients gave written informed consent.

\section{Study population}

Stable patients with COPD referred for pulmonary rehabilitation (PR) to CIRO, a Center of Expertise for Chronic Organ Failure, were consecutively recruited between April 23, 2012 and September 24, 2014 and were included in the current analyses. Patients were classified as COPD based on postbronchodilator $\mathrm{FEV}_{1} / \mathrm{FVC}<0.7$ according to the Global Initiative for Obstructive Lung Disease (GOLD). ${ }^{1}$ COPD Assessment Test (CAT) total score was used as symptom measure for the combined COPD assessment. ${ }^{1}$ When CAT score was missing, the modified Medical Research Council score was used instead. ${ }^{1}$ Stable was defined as not having a registered exacerbation in the past 4 weeks. Patients with a history of other respiratory diseases, having undergone lung surgery, or with a malignancy within the last 5 years were excluded from the study. ${ }^{17}$

\section{Study procedures}

Patients were measured during an inpatient pre-rehabilitation assessment. Clinical characteristics were assessed as described before. ${ }^{16}$ Exacerbation history and hospital and ICU admission were based on the medical report and patient recall. $\mathrm{CB}$ was defined as the presence of chronic cough and sputum production for at least 3 months a year, for two consecutive years. ${ }^{1}$ Disease-specific health status was assessed by CAT, ${ }^{18}$ the Clinical COPD Questionnaire (CCQ), ${ }^{19}$ and the COPD-specific version of the St George's Respiratory Questionnaire (SGRQ-C). ${ }^{20} \mathrm{CAT}$ items on cough and phlegm were stratified based on the number of points reported by patients, with a cutoff of $\geq 3$ points. Besides, the following minimum clinically important differences (MCID) were taken into account: $\geq 2$ points $\mathrm{CAT},{ }^{21} \geq 0.4$ points $\mathrm{CCQ},{ }^{22}$ and $\geq 4$ points SGRQ-C. ${ }^{23}$ Symptoms of anxiety and depression were measured using the Hospital Anxiety and Depression Scale (HADS) ${ }^{24}$ Exercise capacity was assessed by the 6-minute walking distance (6MWD). ${ }^{25}$ Moreover, laboratory data including inflammatory parameters and blood gas analysis were collected. All patients were asked to produce spontaneous sputum if possible. Sputum samples were cultured to obtain the microbial etiology. Patients were categorized into two subgroups: nonsputum producers (NP) and sputum producers (SP), with the last group stratified by culture result; $\mathrm{SP}$ with a negative culture (SC-) and SP with a positive culture $(\mathrm{SC}+)$.

\section{Statistical analysis}

SPSS version 20.0 (IBM Corporation, Armonk, NY, USA) was used for data analyses. Variables were tested for normality using the skewness and kurtosis statistics. Continuous data are presented as mean \pm standard deviation or median (interquartile range), while categorical data are presented as counts and percentages. Subgroups were compared using 
one-way analysis of variance and post hoc Bonferroni test, Kruskal-Wallis test for $\mathrm{k}$ - and 2-independent samples, or chisquare test, as appropriate. A $P$-value $<0.05$ was considered to be statistically significant.

\section{Results}

In total, 518 clinically stable patients with COPD were recruited (mean age 64.1 \pm 9.1 years, 55.6\% males, $\mathrm{FEV}_{1}$ $48.6 \% \pm 20.0 \%$ pred; Table S1). Of these, 164 patients (31.7\%) produced a spontaneous sputum sample during their PR assessment. When comparing NP with SP, SP had a higher number of males, were more often classified as COPD GOLD D, were more frequent exacerbators, had more hospitalizations, and the prevalence of $\mathrm{CB}$ was higher (Table S1).

To see whether these differences between NP and SP could be explained by the sputum microbiology, Table 1 gives an overview of the baseline characteristics of NP, $\mathrm{SC}+$, and $\mathrm{SC}-$. A positive sputum culture was obtained in 53 patients $(32.3 \%)$ with a sample. $\mathrm{SC}+$ were more often males compared with NP, and more frequently classified as COPD GOLD D. No discrimination based on culture result could

Table I Baseline characteristics of NP vs SC- vs SC+

\begin{tabular}{|c|c|c|c|c|}
\hline Features & NP $(n=354)$ & $S C-(n=I I I)$ & $\mathrm{SC}+(n=53)$ & $P$-value \\
\hline Age (years) & $63.8 \pm 9.1$ & $64.3 \pm 9.2$ & $65.5 \pm 8.9$ & 0.466 \\
\hline Male sex & $184(52.0)$ & $68(6 \mid .3)$ & $36(67.9)^{\mathrm{a}}$ & 0.037 \\
\hline BMI $\left(\mathrm{kg} / \mathrm{m}^{2}\right)$ & $26.1 \pm 5.8$ & $26.2 \pm 5.4$ & $27.0 \pm 6.4$ & 0.622 \\
\hline COPD GOLD & & & & $<0.001$ \\
\hline A & $13(3.7)$ & $4(3.6)$ & $2(3.8)$ & \\
\hline B & $162(45.8)$ & $36(32.4)$ & $8(15.1)$ & \\
\hline C & $7(2.0)$ & $3(2.7)$ & & \\
\hline$D$ & $172(48.6)$ & $68(6 \mid .3)$ & $43(8 I . I)^{\mathrm{a}}$ & \\
\hline Current smoker & $72(20.4)$ & $32(28.8)$ & $10(18.9)$ & 0.362 \\
\hline Pack-years ${ }^{\mathrm{b}}$ & $40.0(30.0-50.0)$ & $40.0(25.0-50.0)$ & $4 I .0(31.0-51.0)$ & 0.350 \\
\hline $\mathrm{FEV}_{1}$ (\% predicted) & $49.0 \pm 20.0$ & $48.7 \pm 19.2$ & $45.6 \pm 21.4$ & 0.525 \\
\hline FEV /FVC (Tiffeneau) & $37.9 \pm 12.1$ & $36.8 \pm 11.8$ & $36.5 \pm 13.8$ & 0.579 \\
\hline RV (\% predicted) & $163.0 \pm 51.6$ & $|55| \pm 46.3$. & $160.7 \pm 53.6$ & 0.372 \\
\hline TLC (\% predicted) & $117.9 \pm 17.1$ & $116.2 \pm 17.5$ & I I $3.7 \pm 20.0$ & 0.226 \\
\hline DLCO (\% predicted) & $49.5 \pm 17.5$ & $50.2 \pm 16.9$ & $46.2 \pm 15.8$ & 0.391 \\
\hline LTOT & $82(23.2)$ & $24(21.6)$ & $19(35.8)$ & 0.103 \\
\hline $\mathrm{PaCO}_{2}(\mathrm{kPa})^{\mathrm{b}}$ & $5.2(4.7-5.6)$ & $5.1(4.7-5.6)$ & $5.3(4.9-5.9)$ & 0.340 \\
\hline $\mathrm{PaO}_{2}(\mathrm{kPa})^{\mathrm{b}}$ & $9.6(8.7-10.4)$ & $9.3(8.3-10.3)$ & $9.4(8.4-10.4)$ & 0.397 \\
\hline Exacerbations $(<1$ year $)$ & & & & $<0.001$ \\
\hline 0 & I0I (28.5) & $23(20.7)$ & $4(7.5)$ & \\
\hline 1 & $74(20.9)$ & $17(15.3)$ & $6(11.3)$ & \\
\hline$\geq 2$ & $179(50.6)$ & $71(64.0)^{\mathrm{a}}$ & $43(8 I .1)^{\mathrm{a}}$ & \\
\hline Hospitalizations $(<$ I year) & & & & 0.061 \\
\hline 0 & $204(57.6)$ & $57(5 \mathrm{I} .4)$ & $23(43.4)$ & \\
\hline 1 & $87(24.6)$ & $23(20.7)$ & $14(26.4)$ & \\
\hline$\geq 2$ & $63(17.8)$ & 31 (27.9) & $16(30.2)$ & \\
\hline ICU admissions $(<\mathrm{I} \text { year })^{\mathrm{c}}$ & & & & 0.597 \\
\hline 0 & $312(92.9)$ & $100(95.2)$ & $5 I(98.1)$ & \\
\hline 1 & $21(6.3)$ & $4(3.8)$ & I (I.9) & \\
\hline$\geq 2$ & $3(0.9)$ & $\mathrm{I}(\mathrm{I} .0)$ & - & \\
\hline Symptoms of $C B$ & $89(26.1)$ & $46(45.5)^{\mathrm{a}}$ & $32(61.5)^{\mathrm{a}}$ & $<0.001$ \\
\hline $\mathrm{mMRC} \mathrm{C}^{\mathrm{d}}$ & & & & 0.825 \\
\hline 0 & $7(2.0)$ & $3(2.8)$ & & \\
\hline 1 & $62(17.7)$ & $16(14.7)$ & $7(13.5)$ & \\
\hline 2 & $134(38.2)$ & $42(38.5)$ & $17(32.7)$ & \\
\hline 3 & $82(23.4)$ & $28(25.7)$ & $17(32.7)$ & \\
\hline 4 & $66(18.8)$ & $20(18.3)$ & II (2I.2) & \\
\hline
\end{tabular}

Notes: Data are presented as mean \pm SD, median (interquartile range), or $n$ (\%). ${ }^{a} P<0.05$ compared to NP; ${ }^{b}$ not normally distributed; ${ }^{c}$ missing $N P$ : $n=18$; SC-: $n=6$; SC+: $\mathrm{n}=1$; ${ }^{\mathrm{d}}$ missing NP: $\mathrm{n}=3$; SC-: $\mathrm{n}=2$; $\mathrm{SC}+\mathrm{n}=\mathrm{I}$.

Abbreviations: BMI, body mass index; COPD, chronic obstructive pulmonary disease; GOLD, Global initiative for chronic Obstructive Lung Disease; FEV , forced expiratory volume in I second; FVC, forced Vital capacity; RV, residual volume; TLC, total lung capacity; DLCO, diffusing capacity for carbon monoxide; LTOT, long-term oxygen therapy; CB, chronic bronchitis; mMRC, modified Medical Research Council; ICU, intensive care unit; SD, standard deviation; NP, nonsputum producers; SC+, sputum producers with a positive culture; SC-, sputum producers with a negative culture. 
be made for the number of exacerbations in the year prior to assessment and symptoms of $\mathrm{CB}$, although there was a trend toward increased exacerbations $(P=0.058)$ and symptoms of $\mathrm{CB}(P=0.061)$ in $\mathrm{SC}+\mathrm{vs} \mathrm{SC}-$. In patients with $\mathrm{CB}(\mathrm{n}=167)$, 78 patients produced a spontaneous sputum sample $(46.7 \%)$. No differences were observed in medication use between the defined subgroups (Table S2).

\section{Health status, depression, and anxiety}

Health status using CAT total, cough and phlegm score, SGRQ-C total and symptom score, and CCQ-total score were worse in SP compared to NP (Table S3), although the
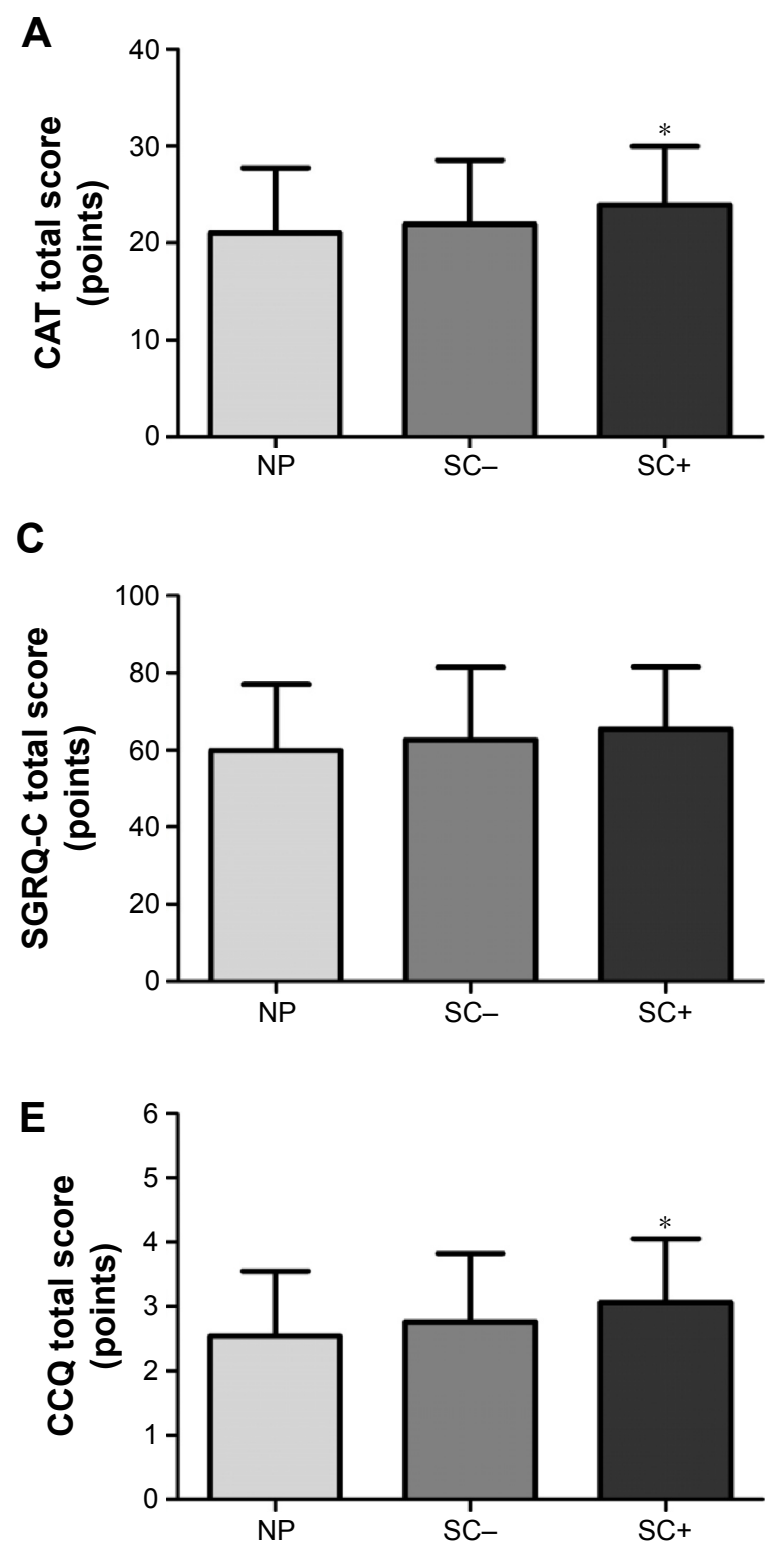

differences did not exceed the MCID for all total scores. The sputum microbiology was discriminating in CAT total (Figure 1) and CCQ total (Figure 1), with worse scores in $\mathrm{SC}+$ compared with NP $(23.9 \pm 6.1$ vs $21.1 \pm 6.7, P=0.012$; $3.1 \pm 1.0$ vs $2.5 \pm 1.0, P=0.002$; respectively). CAT cough and phlegm (Figure 1) and SGRQ-C symptom score (Figure 1) were increased in both $\mathrm{SC}+$ and $\mathrm{SC}$ - compared with $\mathrm{NP}$ (Table S4). SGRQ-C total score was not significantly different anymore when taking the sputum microbiology into account, although the MCID was reached comparing SC+ with NP (65.4 \pm 16.1 vs $60.0 \pm 17.0)$. Additionally, the MCID was reached for SGRQ-C impact comparing SC+ with NP
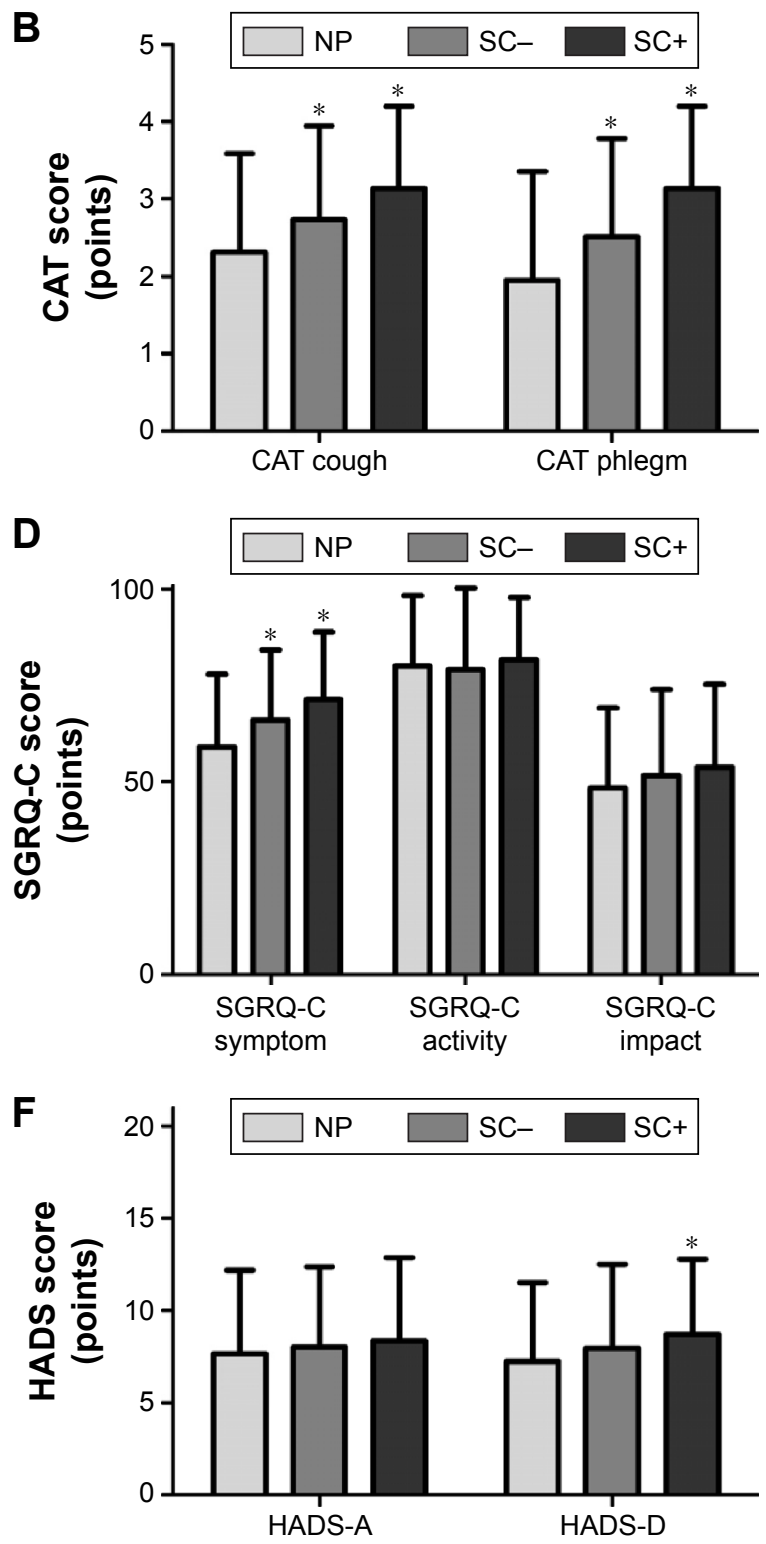

Figure I Health status of NP vs SC- vs SC+ by CAT total score (A), CAT cough and phlegm (B), SGRQ-C total score (C), SGRQ-C domain scores (D), CCQ total score (E), and HADS score (F).

Notes: Data are presented as mean \pm SD. One-way ANOVA and post hoc Bonferroni test. $* P<0.05$ compared to NP.

Abbreviations: CAT, COPD Assessment Test; SGRQ-C, St George's Respiratory Questionnaire; CCQ, Clinical COPD Questionnaire; HADS, Hospital Anxiety and Depression scale; SC-, sputum producers with a negative culture; SC+, sputum producers with a positive culture; SD, standard deviation; ANOVA, analysis of variance; NP, nonsputum producers. 
(53.8 \pm 21.6 vs $48.4 \pm 20.7)$. A significant difference between $\mathrm{SC}+$ and SC- was observed in CAT phlegm $(3.1 \pm 1.1 \mathrm{vs}$ $2.5 \pm 1.3, P=0.020)$ and an MCID in SGRQ-C symptom score (71.3 \pm 17.5 vs $66.0 \pm 18.2$; Table S4).

When stratifying CAT cough and phlegm items based on reported scores, a significantly larger proportion of $\mathrm{SC}+$ and SC- reported scores $\geq 3$ points compared with NP $(38[74.5 \%]$ vs $66[60.6 \%]$ vs $162[47 \%], P<0.001$; 38 [74.5\%] vs $55[50.5 \%]$ vs 134 [38.8\%], $P<0.001$; respectively).

Symptoms of depression by the HADS score (Figure 1F) were more often observed in SC+ compared to NP $(8.7 \pm 4.1$ vs 7.2 \pm 4.3 ). When comparing groups based on the proportion of patients with an elevated score on health status or symptoms of anxiety and depression, no significant differences appeared (Table S5).

\section{Exercise capacity}

Exercise capacity, assessed using the 6MWD, did not differ between NP and SP $(424.8 \pm 124.7$ vs $422.3 \pm 124.1 \mathrm{~m})$.

\section{Inflammatory parameters and microbial etiology}

Table 2 shows the inflammatory parameters, with no differences between NP and SP.

The frequency of the detected pathogens in the 53 patients with positive culture is presented in Figure 2. Haemophilus influenzae was most frequently present (39.6\%), followed by Pseudomonas aeruginosa (28.3\%). Coinfections existed, as a total of eleven patients were positive for more than one pathogen.

\section{Discussion}

The results of this study can be summarized as follows. Almost one-third of patients with COPD referred for PR

Table 2 Inflammatory parameters, by peripheral blood collection, of NP vs SP

\begin{tabular}{|c|c|c|c|}
\hline Features & NP $(n=354)$ & SP $(n=164)$ & $P$-value \\
\hline $\mathrm{CRP}(\mathrm{mg} / \mathrm{L})^{\mathrm{a}}$ & $2.6(0.9-7.0)$ & $3.3(1.1-8.0)$ & 0.158 \\
\hline Erythrocytes $\left(10^{\mathrm{E} 12 / \mathrm{L}}\right)$ & $4.7 \pm 0.4$ & $4.7 \pm 0.5$ & 0.490 \\
\hline Leukocytes $\left(10^{E 9} / \mathrm{L}\right)$ & $8.0 \pm 2.3$ & $8.3 \pm 2.5$ & 0.153 \\
\hline Granulocytes (\%) & $60.7 \pm 9.6$ & $59.5 \pm 10.3$ & 0.198 \\
\hline Lymphocytes (\%) & $28.2 \pm 8.1$ & $28.7 \pm 8.7$ & 0.538 \\
\hline Monocytes (\%) & $8.6 \pm 3.0$ & $9.0 \pm 3.0$ & 0.119 \\
\hline Eosinophilic granulocytes $(\%)^{\mathrm{a}, \mathrm{b}}$ & $3.0(2.0-4.0)$ & $3.0(2.0-5.0)$ & 0.205 \\
\hline$\leq 2 \%$ & $86(45.5)$ & $35(39.3)$ & 0.332 \\
\hline$>2 \%$ & $103(54.5)$ & $54(60.7)$ & 0.205 \\
\hline
\end{tabular}

Notes: Data are presented as mean \pm SD, median (interquartile range), or $n(\%)$. ${ }^{a}$ Not normally distributed; ${ }^{b} n=278$.

Abbreviations: CRP, C-reactive protein; NP, nonsputum producers; SP, sputum producers; SD, standard deviation. were identified as being spontaneous sputum producers. Also, it was shown that patients with COPD who had a sputum sample with a positive culture had worse health status compared with NP. Moreover, these patients had a higher exacerbation frequency and more symptoms of $\mathrm{CB}$. Thus, not the presence of spontaneous sputum production per se, but its microbiological characterization influences outcomes in these patients.

\section{Frequency of spontaneous sputum production}

Spontaneous sputum production at any moment was very common in the present study and was associated with increased CAT cough and phlegm scores and an increased frequency of CB. Previously, Putcha et $\mathrm{al}^{5}$ observed that sputum alone, or in combination with cough, was reported by $43.1 \%$ of 5,887 patients with mild-to-moderate airflow obstruction in the Lung Health Study. A study focusing on symptom variability in 2,441 stable patients with severe COPD showed that sputum was the second most experienced symptom after breathlessness $(63.6 \%) .^{2}$ Although around $30 \%$ of these patients reported a low frequency of sputum production in the past 7 days, $\sim 20 \%$ reported moderate and $\sim 10 \%$ severe or extreme production. ${ }^{2}$ Taking these proportions into consideration, it must be concluded that sputum production is common in patients with $\mathrm{COPD}$, highlighting the potential importance of this specific clinical profile.

\section{Impact on outcomes}

Health status is an important outcome in the management of COPD. Until now, studies showed that health status is worse in patients with symptoms of $\mathrm{CB},{ }^{3,6,26}$ mostly based on SGRQ scores. The results support the finding that health status is worse in patients with sputum production, especially in those with a positive culture (CAT total and CCQ total), even when compared with patients with a negative culture (CAT phlegm and SGRQ-C symptom). So, it seems that sputum production influences the symptom domains, while the sputum microbiology influences health status in general. Within the subgroup of patients with $\mathrm{CB}$, however, health status was not affected by sputum culture. This suggests that sputum microbiology may be clinically relevant, especially in COPD patients with incidental sputum production. Although SGRQ-C total score and the domain score impact were not statistically significantly different, the difference observed between patients with a positive sputum culture and those without sputum production exceeded the MCID.

Limited data are available concerning symptoms of anxiety and depression in relation to $\mathrm{CB}$. Corhay et $\mathrm{al}^{4}$ reported 


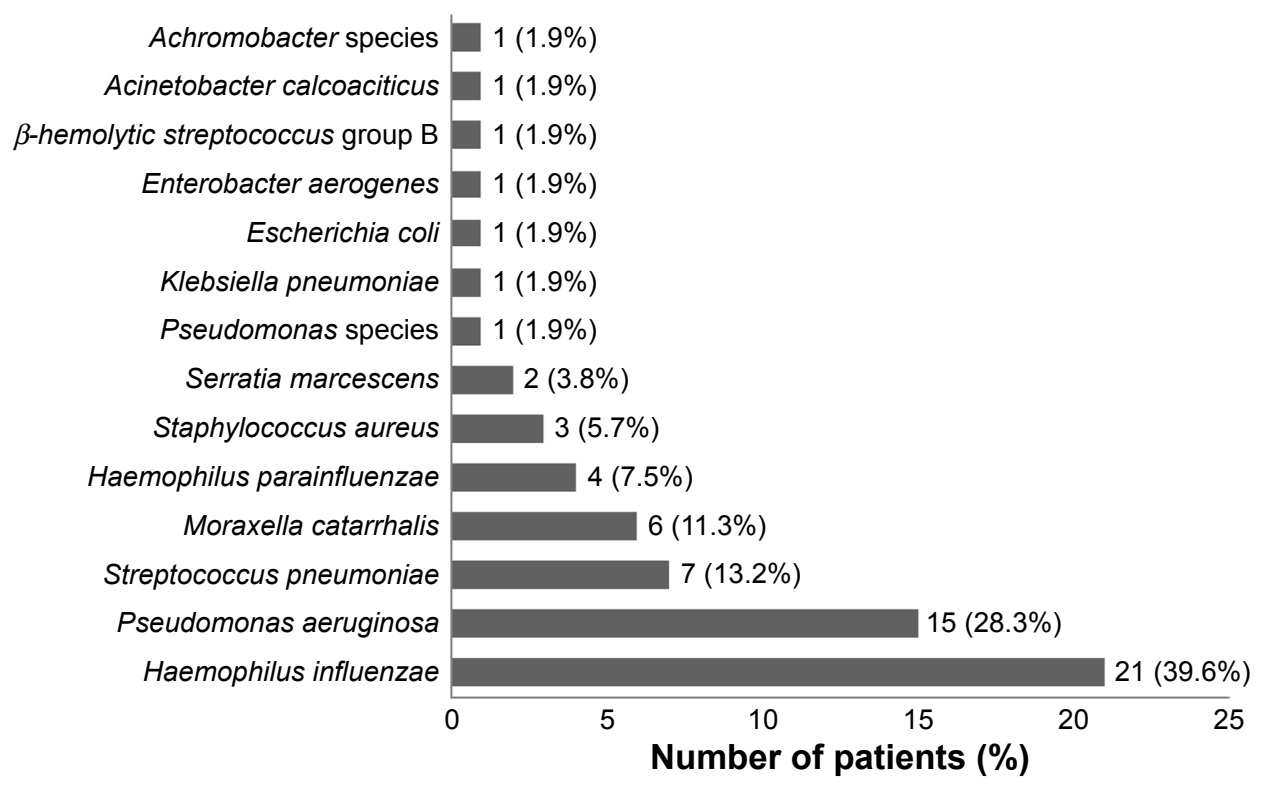

Figure 2 Microbial etiology of sputum producers with a positive culture.

no difference in symptoms of depression comparing patients with and without $\mathrm{CB}$. The current data showed no difference in anxiety scores, although a significantly higher depression score was observed in patients with a positive sputum culture. Whether treatment of CB can lead to a decrease in symptoms of depression is not known and need further research.

It can be argued whether sputum production affects exercise capacity, as no differences were observed in 6MWD, as well as in SGRQ-C activity. Kim et $\mathrm{al}^{6}$ made similar observations in patients with $\mathrm{CB}$. However, this is not supported by others, who observed a reduced 6MWD in patients with CB compared to patients without. ${ }^{3,26}$ In the population of this study, sputum production did not seem to affect exercise capacity at baseline, but it would be interesting to see whether sputum production affects long-term exercise capacity. Moreover, the effect of sputum production on physical activities in daily life would be clinically relevant to investigate.

Remarkably, no differences in inflammatory parameters of blood samples were observed between NP and patients with sputum production. Although all patients were in a clinically stable state at time of assessment, a positive sputum culture may indicate microbial colonization. Indeed, worse outcomes were previously described in colonized patients with COPD concerning exacerbation frequency and daily symptoms, when compared with noncolonized patients. ${ }^{13,14}$ Although the current study design does not allow to firmly establish colonization, it suggests that sputum microbiology, instead of sputum production per se, affects health status.

The observed difference in frequency of sputum production between sexes might be explained by sex-related differences in reporting respiratory symptoms. Lamprecht et $\mathrm{al}^{27}$ observed that females more often reported respiratory symptoms such as dyspnea and cough compared to males. In contrast, males more often reported sputum production. ${ }^{27}$ This in accordance with other studies that observed the same differences between the sexes regarding the presence of $\mathrm{CB} .{ }^{3,6}$

\section{Microbiological characterization}

The sputum microbiology confirms that $H$. influenzae and $P$. aeruginosa are pathogens frequently cultured in patients with COPD. ${ }^{28}$ Especially, H. influenzae is observed in both stable state and during exacerbations. ${ }^{29} P$. aeruginosa is more often found in patients with most severely impaired lung function..$^{30}$ The effect of a specific etiology on the outcomes cannot be studied as the subgroups would become too small.

\section{Strengths and limitations}

The current study was based on a rather homogenous population of clinically stable patients with mild-to-severe COPD referred for PR. Therefore, differences in health status between subgroups are not expected to be associated with COPD-specific characteristics. Subgroups had comparable baseline characteristics concerning their level of airflow obstruction, smoking status, and hospital admissions.

Until now, most analyses ${ }^{3,4,6}$ were based on patients who reported CB. However, it is difficult to assess this phenotype objectively as this definition relies on patients' perception of the symptoms and might be subject to recall bias. Studies that used sputum samples are few in number and are mainly focused on inflammatory parameters. ${ }^{26}$ Moreover, no study 
differentiated patients with sputum samples based on their microbiological culture result. This is, to the best of our knowledge, the first study investigating differences between subgroups of patients with and without sputum production and with and without positive culture. Therefore, the current study increased the understanding of this specific subgroup of patients.

However, some aspects need to be taken into consideration regarding the current study. Although characterized as a patient with $\mathrm{CB}$, more than half of them could not produce sputum during their 3 days' pre-rehabilitation assessment. No sputum induction was performed as part of the current study, so only patients with a spontaneous sample were included in the producer groups. Besides, $\mathrm{SC}+$ were often classified as GOLD D and were frequent exacerbators, which could act as bias. However, it is known that patients with frequent exacerbations are more often colonized, which explains the present outcomes. ${ }^{14}$ Moreover, no high-resolution computed tomography was performed to identify bronchiectasis, which is associated with increased sputum production. ${ }^{31}$

\section{Conclusion}

In conclusion, health status is worse in patients with COPD who spontaneously produce sputum, especially when having a positive culture. Exercise capacity does not seem to be affected by sputum production. Further research is necessary to investigate the influence of sputum production and microbiology in the long term, especially when looking at positive cultures in relation to disease progression and outcomes of PR. Insight into the clinical profile of this subgroup of patients may contribute to specific recommendations, as not sputum per se seems to influence clinical outcomes, but having a positive culture.

\section{Disclosure}

The authors report no conflicts of interest in this work.

\section{References}

1. Global Initiative for Chronic Obstructive Lung Disease. Global Strategy for the Diagnosis, Management, and Prevention of Chronic Obstructive Pulmonary Disease; 2015. Available from: http://www.goldcopd.org/ guidelines-global-strategy-for-diagnosis-management.html. Accessed February 17, 2015.

2. Kessler R, Partridge MR, Miravitlles M, et al. Symptom variability in patients with severe COPD: a pan-European cross-sectional study. Eur Respir J. 2011;37(2):264-272.

3. Kim V, Davey A, Comellas AP, et al. Clinical and computed tomographic predictors of chronic bronchitis in COPD: a cross sectional analysis of the COPDGene study. Respir Res. 2014;15:52.

4. Corhay JL, Vincken W, Schlesser M, Bossuyt P, Imschoot J. Chronic bronchitis in COPD patients is associated with increased risk of exacerbations: a cross-sectional multicentre study. Int J Clin Pract. 2013; 67(12):1294-1301.
5. Putcha N, Drummond MB, Connett JE, et al. Chronic productive cough is associated with death in smokers with early COPD. Copd. 2014; 11(4):451-458.

6. Kim V, Han MK, Vance GB, et al. The chronic bronchitic phenotype of COPD: an analysis of the COPDGene Study. Chest. 2011;140(3): 626-633.

7. Burgel PR, Nadel JA. Epidermal growth factor receptor-mediated innate immune responses and their roles in airway diseases. Eur Respir J. 2008; 32(4):1068-1081.

8. Caramori G, Di Gregorio C, Carlstedt I, et al. Mucin expression in peripheral airways of patients with chronic obstructive pulmonary disease. Histopathology. 2004;45(5):477-484.

9. Vestbo J, Prescott E, Lange P. Association of chronic mucus hypersecretion with FEV1 decline and chronic obstructive pulmonary disease morbidity. Copenhagen City Heart Study Group. Am J Respir Crit Care Med. 1996;153(5):1530-1535.

10. Miravitlles M, Guerrero T, Mayordomo C, Sanchez-Agudo L, Nicolau F, Segu JL. Factors associated with increased risk of exacerbation and hospital admission in a cohort of ambulatory COPD patients: a multiple logistic regression analysis. The EOLO Study Group. Respiration. 2000;67(5):495-501.

11. Peto R, Speizer FE, Cochrane AL, et al. The relevance in adults of airflow obstruction, but not of mucus hypersecretion, to mortality from chronic lung disease. Results from 20 years of prospective observation. Am Rev Respir Dis. 1983;128(3):491-500.

12. Marin A, Monso E, Garcia-Nunez M, et al. Variability and effects of bronchial colonisation in patients with moderate COPD. Eur Respir J. 2010;35(2):295-302.

13. Desai $\mathrm{H}$, Eschberger $\mathrm{K}$, Wrona $\mathrm{C}$, et al. Bacterial colonization increases daily symptoms in patients with chronic obstructive pulmonary disease. Ann Am Thorac Soc. 2014;11(3):303-309.

14. Patel IS, Seemungal TA, Wilks M, Lloyd-Owen SJ, Donaldson GC, Wedzicha JA. Relationhip between bacterial colonisation and the frequency, character, and severity of COPD exacerbations. Thorax. 2002; 57:759-764.

15. Banerjee D, Khair OA, Honeybourne D. Impact of sputum bacteria on airway inflammation and health status in clinical stable COPD. Eur Respir J. 2004;23(5):685-691.

16. Smid DE, Wilke S, Jones PW, et al. Impact of cardiovascular comorbidities on COPD Assessment Test (CAT) and its responsiveness to pulmonary rehabilitation in patients with moderate to very severe COPD: protocol of the Chance study. BMJ Open. 2015;5(7):e007536.

17. Wilke S, Smid DE, Spruit MA, et al. The 2014 updated GOLD strategy: a comparison of the various scenarios. Chron Obstruct Pulmon Dis. 2014;1(2):212-220.

18. Jones PW, Harding G, Berry P, Wiklund I, Chen WH, Kline Leidy N. Development and first validation of the COPD Assessment Test. Eur Respir J. 2009;34(3):648-654.

19. van der Molen T, Willemse BW, Schokker S, ten Hacken NH, Postma DS, Juniper EF. Development, validity and responsiveness of the Clinical COPD Questionnaire. Health Qual Life Outcomes. 2003;1:13.

20. Jones PW, Quirk FH, Baveystock CM, Littlejohns P. A self-complete measure of health status for chronic airflow limitation. The St. George's Respiratory Questionnaire. Am Rev Respir Dis. 1992;145(6):1321-1327.

21. Kon SS, Canavan JL, Jones SE, et al. Minimum clinically important difference for the COPD Assessment Test: a prospective analysis. Lancet Respir Med. 2014;2(3):195-203.

22. Kocks JW, Tuinenga MG, Uil SM, van den Berg JW, Stahl E, van der Molen T. Health status measurement in COPD: the minimal clinically important difference of the clinical COPD questionnaire. Respir Res. 2006;7:62.

23. Jones PW. St. George's Respiratory Questionnaire: MCID. Copd. 2005; 2(1):75-79.

24. Zigmond AS, Snaith RP. The hospital anxiety and depression scale. Acta psychiatr Scand. 1983;67(6):361-370.

25. Spruit MA, Polkey MI, Celli B, et al. Predicting outcomes from 6-minute walk distance in chronic obstructive pulmonary disease. J Am Med Dir Assoc. 2012;13(3):291-297. 
26. Khurana S, Ravi A, Sutula J, et al. Clinical characteristics and airway inflammation profile of COPD persistent sputum producers. Respir Med. 2014;108(12):1761-1770.

27. Lamprecht B, Vanfleteren LE, Studnicka M, et al. Sex-related differences in respiratory symptoms: results from the BOLD Study. Eur Respir J. 2013;42(3):858-860.

28. Sethi S. Infection as a comorbidity of COPD. Eur Respir J. 2010;35(6): 1209-1215.

29. Tufvesson E, Bjermer L, Ekberg M. Patients with chronic obstructive pulmonary disease and chronically colonized with Haemophilus influenzae during stable disease phase have increased airway inflammation. Int J Chron Obstruct Pulmon Dis. 2015;10:881-889.
30. Gallego M, Pomares X, Espasa M, et al. Pseudomonas aeruginosa isolates in severe chronic obstructive pulmonary disease: characterization and risk factors. BMC Pulm Med. 2014;14:103.

31. Gatheral T, Kumar N, Sansom B, et al. COPD-related bronchiectasis; independent impact on disease course and outcomes. Copd. 2014;11(6): 605-614.

\section{Publish your work in this journal}

The International Journal of COPD is an international, peer-reviewed journal of therapeutics and pharmacology focusing on concise rapid reporting of clinical studies and reviews in COPD. Special focus is given to the pathophysiological processes underlying the disease, intervention programs, patient focused education, and self management protocols.

\section{Dovepress}

This journal is indexed on PubMed Central, MedLine and CAS. The manuscript management system is completely online and includes a very quick and fair peer-review system, which is all easy to use. Visit http://www.dovepress.com/testimonials.php to read real quotes from published authors. 